\title{
Total Organic Carbon
}

National Cancer Institute

\section{Source}

National Cancer Institute. Total Organic Carbon. NCI Thesaurus. Code C134114.

An indirect measure of organic molecules present in pharmaceutical waters measured as carbon. 